\title{
Responsibility to carers - an ethical dilemma
}

\author{
JACQUELINE M. AtKInson, Lecturer in Behavioural Science, Department of Community \\ Medicine, University of Glasgow, Glasgow G12 8RZ; and DENISE A. COIA, \\ Consultant Psychiatrist, Florence Street Day Hospital, Glasgow G5
}

The responsibility the health service owes to relatives who care for mentally ill patients is gradually being acknowledged. The Griffiths Report (1988) makes explicit both that families should care for their ill members and that the health service has a duty to provide some support. The new support for the family is more to enable them to be 'better carers' and to cope with the burdens of caring. One area of psychiatry where this support is a growth area is for relatives of people with schizophrenia. Research points to both the impact of some families on the career of the patient, including relapse rates, and the ways in which such negative impact can be reduced (Leff et al, 1989). This paper is concerned with the ethical issues involved in offering a service to relatives. The ethical dilemma of access to relatives is intimately related to the person at whom outcome is aimed.

Access to relatives comes by way of the patient who is central in the chain of communication. Before approaching relatives most psychiatrists would expect to obtain permission from the patient to do this. Very often permission is willingly given; it is only when it is not that we are faced with ethical dilemmas. These usually centre around patient autonomy and relatives' rights.

The type of service offered as regards outcome will influence the position taken on various ethical issues of access: whether the aim of the service to relatives is in terms of outcome for them (information, advice, support for their problem) or outcome for the patient (change in patient behaviour, decrease in relapse rates) either directly or indirectly brought about by changing the relatives' behaviour.

Autonomy is central to a discussion of ethics. To be an autonomous person involves having the ability to be able to choose for oneself, to formulate and implement one's own plans and to govern one's own behaviour by rules or values. Respect for the autonomous person is deeply embedded within most ethical codes. When 'patient's rights' are spoken of they are usually enumerating aspects of respect for the autonomous person. This includes the principle of informed consent, the right to refuse treatment and the right to confidentiality. Thus patients have the right to refuse their doctor (or other health professional) access to their relatives if they, for whatever reason, want to. Such reasons may include concern over confidentiality, the desire to function as an independent adult, disagreement with relatives over aspects of treatment and/or behaviour and differences of opinion over long-term objectives and/or lifestyle. Some patients may not want to live in the family home but are forced to through a paucity of other suitable accommodation. Involving the family in their care may be seen by such patients as adding insult to injury. A few patients may have delusional beliefs about their families which lead them to believe the family means them harm, and thus they do not want the family involved. Carstairs et al (1985) have suggested that refusing to "discuss a patient's affairs without specific permission . .. is difficult to justify".

The crucial issue seems to be whether patients have the right to an exclusive relationship with their doctor when the illness/behavioural problem has an impact on all the family, and relatives are involved in providing care for the patient. Patients expect information they give their doctor, and other information the doctor gains through access to the patient, to remain confidential to that relationship. Confidentiality is not, however, a clear-cut issue. The BMA recognises this. Having said "A doctor must preserve secrecy on all he knows" they give five exemptions to this rule. In evidence to the Government Committee on Privacy, the BMA stated "it is assumed by public and profession alike that any contact with the complex medical machinery of today implies acquiescence in some degree of extended confidence". It could be argued that the patient today has little choice but to accept this "extended confidence" with the reality of multidisciplinary care teams, group practices and the keeping of both written and computer records.

Here the issue is "can confidentiality be compromised to provide a service to relatives?" And if so, how far?

From a practical point of view, involved relatives will already know that there is something wrong with the patient. It is difficult to conceive of someone being treated for schizophrenia and able to withhold all evidence of the illness from those with whom he or she lives. Thus the psychiatrist is not breaking confidentiality in disclosing there is a problem. Are they if they give the problem a name? While it could 
certainly be answered "yes", it would appear that this happens fairly routinely. Indeed, many relatives have been told the diagnosis but not the patient (Atkinson, 1989).

One of the reasons commonly given for breaking confidentiality is when it is in the patient's best interests. It could certainly be argued that it is in the patient's interests to receive good, appropriate care. As more and more research testifies to the importance of family involvement in relapse (Leff $e t$ al, 1989) then it can certainly be argued that withholding such involvement with the family is unethical. Therefore involving relatives in a treatment could be argued as being in the patient's best interests if it results in reduced relapse, even if the patient does not consent to such involvement. This argument, however, compromises other areas of care. If the doctor-patient relationship is damaged, might this not lead to a patient who alienates himself from that doctor, or the medical profession? Will this lead to worse care? How far is involving the relatives communicating a hidden message to patients that we do not think they are capable of managing on their own, and thus reinforcing a dependency role?

A patient's right to refuse treatment involves a detailed consideration of adequacy of disclosure about treatment, competency and the nature of informed consent. A particular problem arises with those patient's who deny they are ill and as a consequence refuse treatment (Roth et al, 1982). Always to insist on treatment "in the patient's best interest" is to fall prey to paternalism, again undermining the patient's autonomy.

An important consideration in whether a patient can refuse access to his or her relatives must surely centre on whether the relatives' involvement is seen as treatment for the patient or as support for the relatives in their own right. In the first case, patients may have grounds for denying access if they so wish. If, however, the patient's denial of access to relatives is because of a false belief (as to his/her illness, likely outcome of relatives' involvement or nature of relatives' involvement, for example) despite the patient being adequately informed of the nature of the involvement, then other rules may apply. If access to relatives is required so as to offer a support service to relatives, with the direct focus of outcome being for the relative rather than the patient, then to allow the patient to deny access to relatives may be to deny relatives "treatment".

\section{Relatives' rights}

As relatives rightly point out, many are the agents of primary care yet they are not given access to necessary information to care for the patient. Such information includes being told the diagnosis, treatment plans including medication, and in some instances to be consulted about all aspects of the patient's management. Instances of patients being discharged home to parents with no warning, let alone consultation, have led the NSF to draw up a Code of Practice for the Discharging Patients (NSF, 1983).

Not all relatives with whom the patients live are, in fact, primary carers in the real sense. A mother may provide meals and perform other chores of caring (including laundry and cleaning) in the way she would for other members of her family, including her husband, but not be directly involved in managing the illness. Is such a mother to be given less information because her child is mentally more competent than a mother who has more care of illness behaviour?

At the time of crisis or acute illness relatives may need more information than when a patient is well maintained on drugs. If a 'need to know' criterion is used for giving relatives information, then education or other support services may be seen as more appropriate at the time of acute illness and admission than when a patient is on maintenance therapy. But not all patients living with relatives are well, and such support services are needed by them also. Giving information on a 'need to know' basis also calls into question which relatives should be involved.

Relatives not directly involved in care, possibly not even living in the same house, may still need support and want information about the illness. This probably applies most often to siblings; they may be aware that one day the burden of care, or at least decisions about care, will fall on them. Their early involvement may help in long-term planning. Those in such a group are also often concerned about the genetic component of the illness in relation to their children and the likelihood of them developing the illness. Although there is academic research relating to the burden on relatives, it is in accounts written by relatives themselves that the full impact of the patient's illness on their lives becomes clear (NSF, 1974; McDonald, 1980). Society has thrust the responsibility for care onto the relatives and thus has a duty towards the relatives to fit them for this role. That some relatives are willing to take on the role of carer does not absolve the statutory services from enabling relatives to care in a way which reduces the burden on them and provides the most appropriate care for the patient. A utilitarian approach makes the provision of such services almost mandatory. In such an argument any indirect benefit to patients is secondary to the positive impact of the service to the relatives.

\section{Resolution}

There are both intellectual and practical resolutions to the ethical dilemma inherent in providing a service 
for relatives. As has already been stated, much depends on the perceived outcome of the service offered, but we can also consider the way in which the service is offered.

The dilemma can be solved most straightforwardly by the belief that offering any service to relatives is in the patient's best interests, whether the outcome for the patient is direct or indirect. The argument is one put forward as a resolution to many problems in most discussions on medical ethics and has received extensive discussion (Bloch \& Chodoff, 1984). Although it can both lead to paternalism or stem from such a viewpoint it is, nevertheless, central.

A utilitarian approach to care clearly demonstrates the desirability of providing services to relatives. No one can doubt, now, the burden of caring for a mentally ill family member. The benefits of providing a service for relatives may outweigh any negative feelings about such a service from patients.

A more practical approach to resolution may be found in the way in which services are offered, as well as the services themselves. Many psychiatrists will already have established a relationship with relatives. Clearly, a service which offers support for the relatives involved in caring can be seen as primarily a service for them, and benefits to the patient are an indirect spin-off. Such a service will deal with problems and burdens of caring; that ignorance or misinformation about their relative's illness is part of the problem indicating that education can be of benefit to relatives directly, rather than assuming benefit only for the patient.

To overcome some possible patient objectives, especially regarding confidentiality, support for relatives can be offered by a different person than the professional most directly involved with the patient. This person may even be of a different discipline from the patient's primary contact. Thus information about the illness can be conveyed, and management discussed, without patients (or, indeed, relatives) fearing that they will be discussed in their absence by someone who has privileged information about them.

This argument can be extended to provide services away from the setting where the patient is treated. Not only could relatives' groups be set up in community settings, but other agencies could be involved, including for example, health education, community education and voluntary organisations. This would involve a wider variety of professionals who have no direct contact with the patient.

The need for patients to agree to access to relatives can be circumvented if services are provided directly to relatives and relatives are allowed to refer themselves. This might still be a problem for relatives who do not know the diagnosis, but could, in the first instance, be overcome by referral to a general support group. For such a service to work it would need to be widely advertised, both at the hospital and elsewhere. This kind of service is already in existence to some extent through self-help groups, ranging from Al-Anon to the National Schizophrenia Fellowship. Such groups are important, and a new service would seek to supplement and complement what they are able to offer, rather than supplanting them, in the support of relatives in the front line of mental health care.

\section{References}

AtKinson, J. M. (1989) To tell or not to tell the diagnosis of schizophrenia. Journal of Medical Ethics, 15, 21-24.

BLOCH, S. \& CHODOFF, F. (1984) Psychiatric Ethics. Oxford: Oxford University Press.

Carstairs, G. M., Early, D. F., Rollin, H. R. \& Wing, J. K. (1985) Informing relatives about schizophrenia. Bulletin of the Royal College of Psychiatrists, 9, 59-60.

GrIFFITHS, SIR RoY (1988) Community Care-Agenda for Action. A Report to the Secretary of State for Social Services. London: HMSO.

LefF, J., Berkowitz, R., Shavit, N., Glass, I. \& Vaughn, C. (1989) A trial of family therapy $v$ a relatives group for schizophrenia. British Journal of Psychiatry, 154, 56-58.

MCDonAld, F. (1980) The Tragedy of Schizophrenia - The Wife's Tale. Surbiton: NSF.

National SChIzOPHRENIA Fellowship (1974) Living with Schizophrenia - by the Relatives. Surbiton: NSF.

(1983) Good Relations. A Code of Practice for Those Discharging Patients. Surbiton: NSF.

Roth, R. H., Applebaum, P. S., SAllee, R., Reynolds, III, C. F. \& HUBER, G. (1982) The dilemma of denial in the assessment of competency to refuse treatment. American Journal of Psychiatry, 139, 910-913. 